\title{
DUAL-LABOR MARKET AND UNEMPLOYMENT COMPENSATION
}

\author{
Taro Abe ${ }^{1}$
}

date of paper receipt:

19.08.2020.

Original Article date of sending to review:

21.08.2020.

doi: 10.2478/eoik-2020-0012 date of review receipt:

23.09.2020.

UDK 331.5:316.662-055.2

${ }^{1}$ Nagoya Gakuin University, Department of Economics, Japan

\begin{abstract}
This paper discusses the impact of unemployment compensation on the employment and wages of regular and non-regular labor in a dual-labor market. The model in this paper assumes an effective demand constraint and an imperfectly competitive market. The results obtained are as follows. An increase in unemployment compensation increases the wages of regular labor to maintain its productivity. However, this temporarily decreases the employment of regular labor, so that the productivity and wages of non-regular labor decrease. The result is an increase in the relative wage rate of regular labor and the relative amount of non-regular labor employed. This result is independent of any economic regime. In terms of the impact on employment volume, the existence of two regimes, one wage-driven and one profit-driven, is confirmed. However, the effect on employment is weaker if unemployment compensation is financed by taxing profits.
\end{abstract}

\section{Keywords:}

Dual labor market, unemployment compensation, wage-led economy, Egalitarian policy, Post Keynesian, Globalization 


\section{INTRODUCTION}

In recent years, the issue of poverty and inequality has received a lot of attention worldwide. Thus, there is a need for specific policies to address the problem. On this issue, non-mainstream macroeconomists who emphasize demand factors have discussed the effectiveness of incorporating social wages (e.g., unemployment compensation) into their models. Bowles and Boyer (1992) used such a model to explain the expansion of welfare policies in countries of the 1960s and the related setbacks since the 1970s. The upward pressure on wages was not so great during the low-employment period of the 1950s, and the wage increases resulting from the expansion of state welfare policies in the 1960s were able to increase effective demand and achieve the prosperity known as "golden capitalism." However, the ensuing expansion of employment created upward pressure on wages, which, in turn, created profit compression. This led to the emergence of neoliberal policies from the 1970s onwards. Although the cited study is 30 -years old, one of the major differences between then and today is the informalization of labor and the development of globalization. Bowles (2012) argued that under increasing globalization, traditional egalitarian policies (e.g., expanding unemployment compensation) were ineffective because they resulted in capital flight.

There has been a vast amount of theoretical analysis on dual labor markets, which can be divided into two main categories. One, like Saint-Paul (1997), a leading study in the field, incorporates the hiring behavior of firms and the labor supply behavior of workers, but does not make explicit the goods market. The other is a post-Keynesian study that makes goods markets explicit while ignoring the hiring behavior of firms and the labor supply behavior of workers, as is typical of Sonoda and Sasaki (2017). In this context, Nakatani (2013) is a very rare study in that it constructs a dual labor market model that takes into account the employment behavior of firms, the labor supply behavior of workers, and the goods market together. Nakatani (2013) discussed the impact of a minimum-wage increase on employment using a dual-labor-market model consisting of regular and non-regular labor that accounted for effective demand constraints.

A summary of the paper of Nakatani (2013) is as follows. First, the efficiency wage hypothesis, in which wages and labor productivity are positively related to regular labor, is plausible, and profit maximization is performed by firms facing imperfect competition on the basis of a constant elastic-of-substitution (CES)-type production function. Next, households supply regular and non-regular labor to maximize the utility that depends on consumption and leisure. Some researchers believe that unemployment exists in the non-regular labor market, because non-regular employment is determined by the demand for labor by firms. However, the wages of non-regular labor are determined by the goods market. Such a model uses simulations to analyze changes in employment, because the wages of non-regular labor, as determined by the goods market, are gradually raised from the equilibrium level. It is assumed that the wages of non-regular labor are bound by the minimum-wage system. Note that a change in the wages of 
non-regular labor would create an imbalance in the goods market, but the model is such that independent demand other than that of consumption would change and absorb the imbalance.

Based on this model, it can be shown that an increase in the minimum wage will reduce employment of non-regular labor. However, it may also increase the employment of regular labor. The numerical example of minimum-wage increasing the employment of regular labor is obtained when the price elasticity of demand is low. This result can be attributed to the effect of substitution from non-regular and regular labor, because it is easier to pass-on the wage increase as higher prices.

Currently, an analysis that considers both regular and non-regular labor is essential to understanding egalitarian policies. This paper makes some modifications to Nakatani's (2013) model, suggesting that the traditional egalitarian policy of expanding unemployment compensation identifies the impact on wages and employment in the dual-labor market.

The model of Nakatani (2013) analyzes firm behavior under imperfectly competitive markets, but it does not explicitly aggregate individual firms. Thus, we use Adachi (2000) as a reference for aggregation. Additionally, Nakatani (2013) shows that the retained wages for regular work consists of the expected wage if one gets a regular job elsewhere and the expected wage if one does not get a regular job. This paper articulates the wage income of non-regular labor as expected wages in the absence of a regular job.

This paper makes these changes to the model of Nakatani (2013). However, to avoid complications, the production function is a Cobb-Douglas-type first-order approach. Under these assumptions, we discuss the impact of changes in unemployment compensation on employment and wages. First, the structure of the model is explained in Section 2, followed by a comparative statistical analysis in Section 3. Finally, a conclusion is provided in Section 4.

\section{MODEL STRUCTURE}

Suppose that enterprise $i$ employs two types of workers (regular and non-regular) to produce goods. If the production function is a Cobb-Douglas type, it can be expressed as

$$
y_{i}=A\left(\theta_{i} n_{1 i}\right)^{\alpha} n_{2 i}^{1-\alpha}, \quad 0<\alpha<1,
$$

where $y_{i}$ represents the output, A represents the element-neutral productivity, $\theta_{i}$ represents the labor productivity of regular labor, $n_{1 i}$ represents the employment of regular labor, and $n_{2 i}$ represents the employment of non-regular labor.

Next, if we assume the efficiency-wage hypothesis that labor productivity depends on the wages of regular labor, then the labor productivity of regular labor, $\theta_{i}$, can be written as

$$
\theta_{i}=\left(w_{1 i}-x_{i}\right)^{\beta}, \quad 0<\beta<1,
$$

where $w_{1 i}$ is the real wage rate of regular labor, and $x_{i}$ is the reserved wage of regular labor. Note that, although not directly related to this paper, see Radukic, S., Mastilo, Z., Kostic, Z., \& Vladusic, Lj. (2019) for a definition of labor market efficiency. Assuming that firm $i$ faces an imperfectly competitive market, the demand function can be expressed as 


$$
p_{i}=P\left(\frac{y_{i}}{E_{i}}\right)^{-\frac{1}{\epsilon}}, \quad \quad \varepsilon>1,
$$

where $p_{i}$ is the price faced by individual firms, $\mathrm{P}$ is the general price level, $E_{i}$ is a parameter representing expected demand, and $\varepsilon$ is the price elasticity of demand. Equation (3) shows that as the relative price of good i increases, the relative demand for good i decreases. The price elasticity of demand is assumed to be greater than one to satisfy the profit-maximizing condition.

Considering Eqs. (1)-(3), the profit of the firm, $\Pi_{i}$, can be expressed as

$$
\Pi_{i}=p_{i} y_{i}-P w_{1 i} n_{1 i}-P w_{2 i} n_{2 i}=P E_{i}^{\frac{1}{\epsilon}} y_{i}^{1-\frac{1}{\varepsilon}}-P w_{1 i} n_{1 i}-P w_{2 i} n_{2 i},
$$

where $w_{2 i}$ is the real wage rate for non-regular labor.

Firm $i$ maximizes profit $\Pi_{i}$ and determines the amount of employment of regular labor, $n_{1 i}$, the amount of non-regular work employed, and $n_{2 i}$ is the real wage rate of regular employment, $w_{1 i}$. Thus, the first order conditions for profit maximization are as follows:

$$
\begin{gathered}
\frac{\partial \Pi_{i}}{\partial n_{1 i}}=P E_{i}^{\frac{1}{\epsilon}}\left(1-\frac{1}{\epsilon}\right)\left[\mathrm{A}\left(\theta_{i} n_{1 i}\right)^{\alpha} n_{2 i}^{1-\alpha}\right]^{-\frac{1}{\epsilon}} A n_{2 i}^{1-\alpha} \alpha\left(\theta_{i} n_{1 i}\right)^{\alpha-1} \theta_{i}-P w_{1 i}=0, \\
\frac{\partial \Pi_{i}}{\partial n_{2 i}}=P E_{i}^{\frac{1}{\epsilon}}\left(1-\frac{1}{\epsilon}\right)\left[\mathrm{A}\left(\theta_{i} n_{1 i}\right)^{\alpha} n_{2 i}^{1-\alpha}\right]^{-\frac{1}{\epsilon}} A n_{2 i}^{-\alpha}(1-\alpha)\left(\theta_{i} n_{1 i}\right)^{\alpha}-P w_{2 i}=0, \\
\frac{\partial \Pi_{i}}{\partial w_{1 i}}=P E_{i}^{\frac{1}{\epsilon}}\left(1-\frac{1}{\epsilon}\right)\left[\mathrm{A}\left(\theta_{i} n_{1 i}\right)^{\alpha} n_{2 i}^{1-\alpha}\right]^{-\frac{1}{\epsilon}} A n_{2 i}^{1-\alpha} \alpha\left(\theta_{i} n_{1 i}\right)^{\alpha-1} n_{1 i} \beta\left(w_{1 i}-x_{i}\right)^{\beta-1}-P n_{1 i}=0 .
\end{gathered}
$$

For the second-order condition, see Appendix 1.

From Eqs. (5) and (6), we can derive the following equation:

$$
n_{2 i}=\frac{w_{1 i}}{w_{2 i}} \frac{1-\alpha}{\alpha} n_{1 i} .
$$

Then, from Eqs. (5) and (7), we obtain the following equation:

$$
w_{1 i}=\frac{x_{i}}{1-\beta}
$$

Substituting Eq. (9) into Eq. (2) gives the following equation:

$$
\theta_{i}=\left(\beta w_{1 i}\right)^{\beta} .
$$

Substituting Eq. (8) into Eq. (5), we get the following equation:

$$
n_{1 i}=E_{i}\left(1-\frac{1}{\epsilon}\right)^{\epsilon} A^{\epsilon-1} \alpha^{\epsilon \alpha+1-\alpha} \theta_{i}^{\alpha(\epsilon-1)}(1-\alpha)^{(1-\alpha)(\epsilon-1)}\left(\frac{w_{1 i}}{w_{2 i}}\right)^{(1-\alpha)(\epsilon-1)} w_{1 i}^{-\epsilon} .
$$

Substituting Eq. (11) into Eq. (8), we get the following equation:

$$
n_{2 i}=E_{i}\left(1-\frac{1}{\epsilon}\right)^{\epsilon} A^{\epsilon-1} \alpha^{\epsilon \alpha-\alpha} \theta_{i}^{\alpha(\epsilon-1)}(1-\alpha)^{(1-\alpha)(\epsilon-1)+1}\left(\frac{w_{1 i}}{w_{2 i}}\right)^{(1-\alpha)(\epsilon-1)+1} w_{1 i}^{-\epsilon} .
$$

Next, we follow the work of Adachi (2000) to aggregate the firms. Here assuming that all firms have the same production technology and face the same demand function, they will have made the same decision. Thus, $w_{1 i}=w_{1}, w_{2 i}=w_{2}, p_{i}=P$, and $E_{i}=E$ hold. Therefore, from Eqs. (10)-(12), we have $\theta_{i}=\theta, n_{1 i}=n_{1}$, and $n_{2 i}=n_{2}$. Finally we have $y_{i}=y$ from Eq. (1).

Next, we consider the retained wage rate, $x_{i}$, for the loss of the current regular job in $i$ firms. A worker who loses his or her current regular job could fall into one of three cases: finding a 
regular job again, finding a non-regular job, or becoming unemployed. Let the overall macroeconomic labor supply be $L$ and the expected wage rate when one gets a regular job be $w_{1}^{e}$. The expected wage rate at the time of gaining a non-regular job is $w_{2}^{e}$. Letting the expected income at the time of unemployment be $w_{u}$, the retained wage is as follows. Note that $w_{u}$ usually corresponds to unemployment compensation. However, it is also considered to include things like welfare. As noted in Bowles (2012) and Bowles and Boyer (1990), this expansion is an important egalitarian policy.

$$
x_{i}=\frac{N_{1}}{L} w_{1}^{e}+\frac{N_{2}}{L} w_{2}^{e}+\left(1-\frac{N_{1}+N_{2}}{L}\right) w_{u},
$$

where $N_{1}$ and $N_{2}$ are the amounts of regular and non-regular work employed in the entire macroeconomy. If the number of firms is $m$, then $N_{1}=m n_{1}$ and $N_{2}=m n_{2}$ holds.

If we follow Adachi (2000) and assume that the expected wage rate is equal to the real wage rate when considering the overall macroeconomic problem, we have $w_{1}^{e}=w_{1}$ and $w_{2}^{e}=w_{2}$. Thus, Eq. (13) can be rewritten as

$$
x=\frac{N_{1}}{L} w_{1}+\frac{N_{2}}{L} w_{2}+\left(1-\frac{N_{1}+N_{2}}{L}\right) w_{u} .
$$

Note that $w_{1}>w_{2}>w_{u}$ is assumed to hold.

In the same way, we can rewrite Eqs. (8)-(11) as

$$
\begin{gathered}
N_{2}=\frac{w_{1}}{w_{2}} \frac{1-\alpha}{\alpha} N_{1}, \\
w_{1}=\frac{x}{1-\beta}, \\
\theta=\left(\beta w_{1}\right)^{\beta}, \\
N_{1}=m E\left(1-\frac{1}{\epsilon}\right)^{\epsilon} A^{\epsilon-1} \alpha^{\epsilon \alpha+1-\alpha} \theta^{\alpha(\epsilon-1)}(1-\alpha)^{(1-\alpha)(\epsilon-1)}\left(\frac{w_{1}}{w_{2}}\right)^{(1-\alpha)(\epsilon-1)} w_{1}^{-\epsilon} .
\end{gathered}
$$

Then, if we consider that the expected demand, $E$, coincides with the actual output, $y$, we obtain the following equation:

$$
y=E \text {. }
$$

Therefore, if the total output is $Y$, then $Y=m y=m E$. Thus, Eq. (18) can be rewritten as

$$
N_{1}=Y\left(1-\frac{1}{\epsilon}\right)^{\epsilon} A^{\epsilon-1} \alpha^{\epsilon \alpha+1-\alpha} \theta^{\alpha(\epsilon-1)}(1-\alpha)^{(1-\alpha)(\epsilon-1)}\left(\frac{w_{1}}{w_{2}}\right)^{(1-\alpha)(\epsilon-1)} w_{1}^{-\epsilon} .
$$

Next, we consider the labor-supply behavior of households. Each household supplies $l_{1}$ and $l_{2}$ amounts of formal and informal labor from the labor supply, $\bar{l}$, and receives unemployment compensation, $w_{u}$, in the event of unemployment. Thus, the consumption function, $c$, for each household is

$$
\mathrm{c}=w_{1} l_{1}+w_{2} l_{2}+w_{u}\left(\bar{l}-l_{1}-l_{2}\right) \text {. }
$$

Each household is assumed to maximize the following utility function, which accounts for consumption and leisure:

$$
\mathrm{u}=c^{\beta}\left(\bar{l}-l_{1}-l_{2}\right)^{1-\beta} .
$$

Assuming that the amount of regular labor, $l_{1}$, is determined by the amount of regular labor 
employed by the firm. Each household chooses $l_{2}$, such that it maximizes the utility function, $U$, because the amount of non-regular labor, $l_{2}$, is what the household can choose.

The resulting consumption function, $c$, for each household is

$$
\mathrm{c}=\beta\left(\bar{l}-l_{1}\right) w_{2}+\beta w_{1} l_{1} .
$$

See Appendix 2 for the calculation process.

If the number of households is $n$, then total consumption, $C$, can be expressed as

$$
\mathrm{C}=\mathrm{nc}=\beta\left[\left(w_{1}-w_{2}\right) \mathrm{n} l_{1}+w_{2} \mathrm{n} \bar{l}\right]=\beta\left[\left(w_{1}-w_{2}\right) N_{1}+w_{2} \mathrm{~L}\right] .
$$

Because we assume that the employment and supply of regular labor are the same, $\mathrm{n} l_{1}=N_{1}$ holds. Additionally, because the labor supply of the economy as a whole is the labor supply of each household multiplied by the number of households, $\mathrm{n} \bar{l}=\mathrm{L}$ holds.

Then, by substituting Eqs. (8) and (19) into Eq. (4) while being conscious of aggregation, we obtain the following real gross profit, $\frac{\Pi}{P}$ :

$$
\frac{\Pi}{P}=\frac{w_{1} N_{1}}{(\epsilon-1) \alpha} .
$$

If we assume that investment is an increasing function of real gross profit, $\frac{\Pi}{P}$, then we can express the investment function, I, as follows:

$$
\mathrm{I}=\gamma+\delta \frac{\Pi}{P} \quad \gamma, \delta>0 .
$$

Considering Eqs. (24)-(26), the equilibrium equation for the goods market is

$$
\mathrm{Y}=\mathrm{C}+\mathrm{I}=\beta\left[\left(w_{1}-w_{2}\right) N_{1}+w_{2} \mathrm{~L}\right]+\gamma+\delta \frac{w_{1} N_{1}}{(\epsilon-1) \alpha} .
$$

Then, using Eqs. (1) and (15), the total production, $\mathrm{Y}=\mathrm{my}$, can be expressed as

$$
\mathrm{Y}=\frac{w_{1} \epsilon}{\alpha(\epsilon-1)} N_{1}
$$

See Appendix 3 for the calculation process.

Assuming that an adjustment for regular employment takes place in the goods market, we obtain the following equation:

$$
\dot{N}_{1}=a\left\{\beta\left[\left(w_{1}-w_{2}\right) N_{1}+w_{2} L\right]+\gamma+\delta \frac{w_{1} N_{1}}{(\epsilon-1) \alpha}-Y\right\}, \quad a>0 .
$$

Equation (29) shows that, if the goods market is in excess demand, the amount of formal employment, $N_{1}$, will increase.

Next, we assume that the adjustment equation for the wage, $w_{1}$, of regular labor is as follows:

$$
w_{1}=b\left\{x L-(1-\beta) w_{1} L\right\}, \quad \mathrm{b}>0 .
$$

Equation (30) shows that the wage of regular labor, $w_{1}$, increases when the actual wage is lower than the optimal wage for eliciting labor effort (i.e., when $\frac{x}{1-\beta}>w_{1}$ ).

We have thus derived the necessary equation, and the model can now be aggregated into seven equations (i.e., (15)-(17), (20), and (28)-(30)) and seven endogenous variables, $w_{1}, \mathrm{x}, \theta, N_{1}, N_{2}$, 
$w_{2}$, and $\mathrm{Y}$.

The model works as follows. First, we suppose that $N_{1}$ and $w_{1}$ take on some value in the dynamic equations of (29) and (30). Then, $\mathrm{x}$ is determined from Eq. (16), $\theta$ is derived from Eq. (17), and $\mathrm{Y}$ is determined from Eq. (28). Therefore, $w_{2}$ is determined from Eq. (20), and $N_{2}$ is determined from Eq. (15). After the above variables are determined, the dynamic equations of (29) and (30) determine $N_{1}$ and $w_{1}$, respectively. Again, the other variables are determined.

In the next section, we present a comparative statics analysis based on the above model to analyze the impact of unemployment compensation on wages and employment.

\section{COMPARATIVE STATICS ANALYSIS}

In this section, we discuss how changes in unemployment compensation, $w_{u}$, are related to the employment and wages of regular and non-regular labor by applying a comparative statics analysis. The results are shown in Table 1. See Appendix 4 for the stability conditions and calculation process.

Table 1. Results of comparative static analysis on $w_{u}$

\begin{tabular}{|l|c|c|c|c|c|c|}
\hline & $w_{1}$ & $w_{2}$ & $N_{1}$ & $N_{2}$ & $\frac{w_{1}}{w_{2}}$ & $\frac{N_{1}}{N_{2}}$ \\
\hline Wage-led & + & - & + & + & + & - \\
\hline Profit-led & + & - & - & \pm & + & - \\
\hline
\end{tabular}

Source: Created by the author

An increase in unemployment compensation, $w_{u}$, leads to an increase in wages, $w_{1}$, to maintain productivity. However, it results in a decrease in wages, $w_{2}$, for non-regular work. This is because the increase in wages for regular labor reduces their employment and reduces the productivity of non-regular labor. Thus, the relative wage of regular labor, $\frac{w_{1}}{w_{2}}$, increases, and the relative employment of regular labor, $\frac{N_{1}}{N_{2}}$, decreases. These results do not depend on the regime of the economy, which we discuss below.

An increase in $w_{1}$ increases consumption, but it decreases investment from reduced profits. Thus, the size of the two effects determines the effect on the amount of regular labor employed, $N_{1}$. When the former is large, we have a wage-led economy, in which both $N_{1}$ and $N_{2}$ of regular labor are increased. When the latter is large, the economy is profit-led, at which time, the amount of regular employment, $N_{1}$, decreases. However, the impact on the amount of non-regular employment, $N_{2}$, is not determined. Note that the effect on utility is indeterminate for both economic regimes. The case of the wage-led economy is easier to understand, but the impact on utility is undetermined, because consumption increases. Additionally, the amount of labor and 
leisure time decreases.

Fig. 1 shows an example of a wage-led economy. An increase in unemployment

Figure 1. Example of a wage-led economy

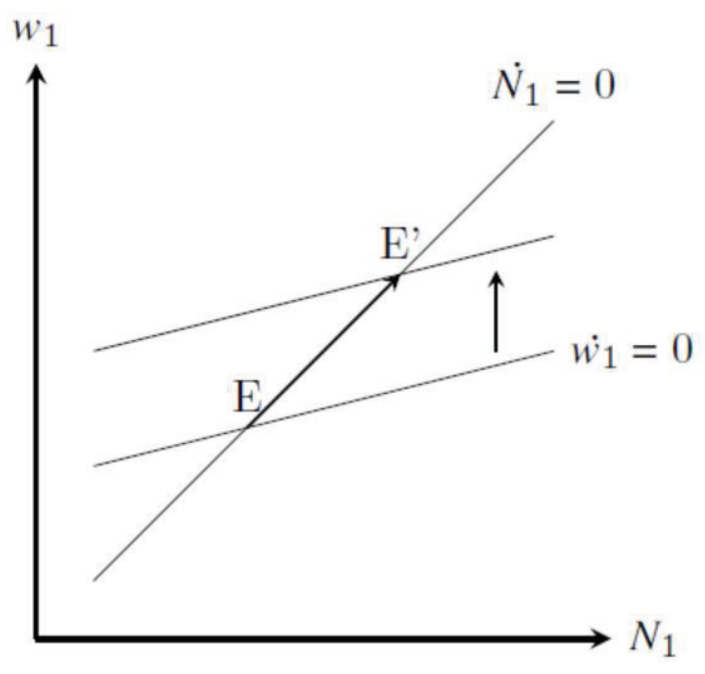

Source: Created by the author

compensation shifts the straight line of $\dot{w}=0$ upward, and wages and employment in regular labor increase. The wage-led economy is characterized by a rightward shift in the straight line of $N_{1}=0$. This shows that wage growth in the goods market increases effective demand. Note that the straight line of $\dot{w}=0$ could be a downward line to the right, but the essence of the argument remains the same.

Fig. 2 shows an example of a profit-led economy. In this case, the straight line of $\dot{N}_{1}=0$ is downward and to the right. Thus, the increase in unemployment compensation reduces the employment of regular labor.

Figure 2. Example of a profit-led economy

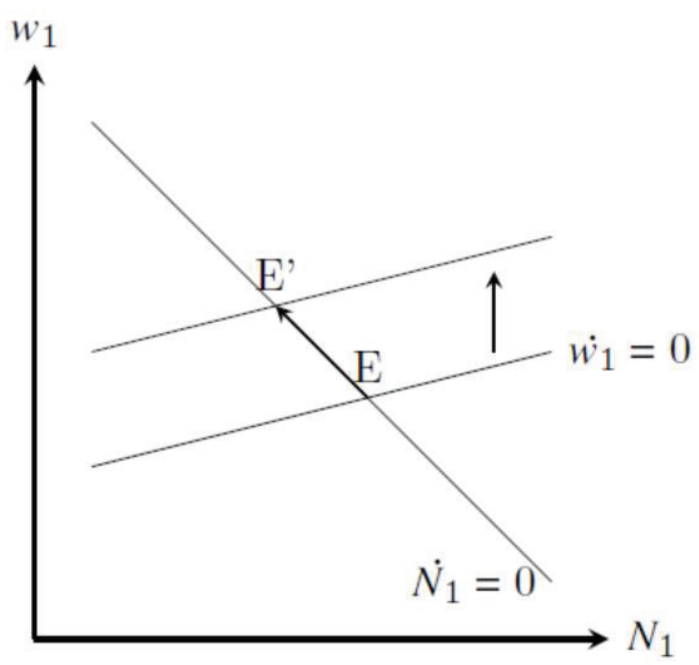


The above corresponds to the discussion presented by Bowles and Boyer (1992). Fig. 3 shows the impact of the increase in unemployment compensation from Bowles and Boyer (1992), but the effect of increased demand for goods was shown in the goods market, unlike that which is shown in Fig. 1 and 2. In other words, in Bowles and Boyer (1992), the increase in unemployment compensation led to an increase in consumption demand and an increase in demand for goods. Note that Bowles and Boyer (1992) did not distinguish between regular and non-regular work, but they adopted the efficiency wage hypothesis, which corresponds to the formal labor-market discussion in this paper.

Figure 3. Impact of increased unemployment compensation in Bowles and Boyer (1992)

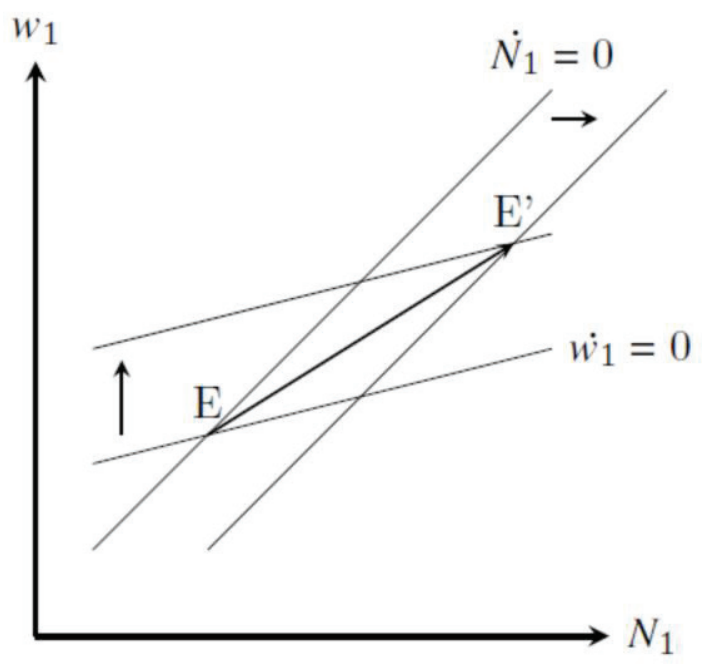

Source: Created by the author

The model assumes utility maximization by representative households, and an increase in unemployment compensation does not lead to an increase in consumption, because the income effect leads to a decrease in the supply of regular labor. Therefore, unemployment compensation has no impact on the goods market. If we assume heterogeneous households having different incomes and a progressive taxation system to finance unemployment compensation, then an increase in unemployment compensation implies a redistribution of income to households having a lower propensity to consume. Thus, effective demand in the goods market will increase. In this regard, we must test to see whether the analysis by representative households is appropriate in light of reality.

Next, we consider the case where unemployment compensation is financed by taxing profits. This is the simplest expression of the income redistribution policy and can be expressed in the following equation:

$$
\left(\mathrm{L}-N_{1}-N_{2}\right) w_{u}=t \frac{w_{1} N_{1}}{(\epsilon-1) \alpha}
$$

where $t$ is the tax rate relative to profit, with the right-hand side representing tax revenues and the left-hand side representing the total amount of unemployment compensation. 
Taking the above into account, the investment function is

$$
\mathrm{I}=\gamma+\delta \frac{(1-t) w_{1} N_{1}}{(\epsilon-1) \alpha}
$$

Substituting Eqs. (15) and (32) into Eq. (33) gives the following equation:

$$
\mathrm{I}=\gamma+\delta\left[\frac{w_{1} N_{1}}{\epsilon-1}-\left(L-N_{1}-\frac{w_{1}}{w_{2}} \times \frac{1-\propto}{\propto} N_{1}\right) w_{u}\right] .
$$

Thus, the goods market is different from previous models.

In the presence of a tax on profits, an increase in unemployment compensation, $w_{u}$, does not necessarily increase wages $w_{1}$ in regular employment. See Appendix 5 for the calculation process of the stability conditions and comparative static analysis.

An increase in $w_{u}$ works to increase $w_{1}$ to maintain labor effort, but an increase in taxes leads to a decrease in profits. Thus, a decrease in investment occurs, which reduces effective demand in the goods market and works to reduce the amount of regular labor employed, $N_{1}$. This effect works to reduce the wage, $w_{1}$, required to sustain labor effort. The relationship between these two effects, large and small, determines the movement of wage $w_{1}$. Fig. 4 shows the case where the latter effect is exceeded, and the wage of regular employment is reduced.

Figure 4. When the wages of regular employees are reduced.

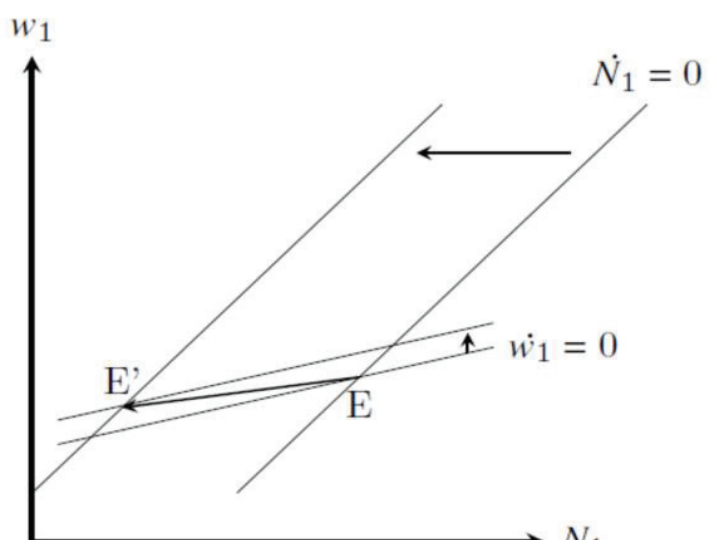

Source: Created by the author 


\section{CONCLUSION}

In this paper, we analyzed the impact of increased unemployment compensation on wages and employment in the dual labor market by explicitly aggregating and modifying the Nakatani (2013) model with respect to retained wages.

The results obtained are as follows. An increase in unemployment compensation increases the wages of regular labor to maintain its productivity, but this works to reduce the employment of regular labor. This also reduces the productivity of regular labor and decreases the wages of non-regular labor. This results in an increase in the relative wage rate of regular labor and relative volume of non-regular labor employed. This result is independent of the economic regime. The existence of two regimes, wage- and profit-led, in terms of their effects on the volume of employment is confirmed, but the effect on employment is weaker when unemployment compensation is financed by a tax on profits.

What policy implications can be drawn from the above results? Bowles (2012) argued that traditional egalitarian policies, such as increasing unemployment compensation, were ineffective in an increasingly globalized world, because they lead to capital flight.

In contrast, Onaran (2019) argued that, if countries adopt coordinated policies, such as simultaneously increasing public investment, it is possible to achieve wage-driven growth with globalization by strengthening workers' bargaining power, even under globalization, based on a progressive taxation system. An assessment of these arguments is beyond the scope of this paper, but we can see from our results that, with any economic regime, the increase in unemployment compensation reduces the wages of regular labor. Therefore, for egalitarian policies to be successful, they must be simultaneously complemented. Note that Skott (2017) questioned this wage-led growth argument. This paper eschews the criticism of the exogenous nature of the income distribution rate that takes place there and the disregard for the labor market.

This paper adopted a Cobb-Douglas-type production function to simplify the analysis. However, this precludes the analysis of cases wherein formal and informal work are not very substitutable. In the future, as with Nakatani (2013), it will be necessary to conduct analysis using a CES-type production function. We can also assume that representative households must consider heterogeneous households. These points will be addressed in future works.

\section{ACKNOWLEDGEMENTS}

This research reports some of the results of the 2019 Nagoya Gakuin University mid-term study-abroad program. We thank Takeshi Nakatani, Masao Yamaguchi, and Junpei Tanaka for serving as our discussion partners as we prepared this paper. We would also like to thank James Juniper for his personal and professional support during the program. Additionally, we thank all of the faculty and staff of Nagoya Gakuin University for their continued support. The usual disclaimer applies. 


\section{Appendix 1}

Organizing Eqs. (5)-(7), we obtain the following three equations:

$$
\begin{gathered}
\frac{\partial \Pi_{i}}{\partial n_{1 i}}=P E_{i}^{\frac{1}{\epsilon}}\left(1-\frac{1}{\epsilon}\right) A^{1-\frac{1}{\epsilon}} \alpha n_{2 i}^{-\frac{1-\alpha}{\epsilon}+1-\alpha} \theta_{i}^{\alpha-\frac{\alpha}{\epsilon}} n_{1 i}^{-\frac{\alpha}{\epsilon}+\alpha-1}-P w_{1 i}=0, \\
\frac{\partial \Pi_{i}}{\partial n_{i 2}}=P E_{i}^{\frac{1}{\epsilon}}\left(1-\frac{1}{\epsilon}\right) A^{1-\frac{1}{\epsilon}} \alpha n_{2 i}^{-\frac{1-\alpha}{\epsilon}-\alpha}\left(\theta n_{1 i}\right)^{\alpha-\frac{\alpha}{\epsilon}}-P w_{2 i}=0, \\
\frac{\partial \Pi_{i}}{\partial w_{i 1}}=P E_{i}^{\frac{1}{\epsilon}}\left(1-\frac{1}{\epsilon}\right) A^{1-\frac{1}{\epsilon}} \alpha \beta n_{2 i}^{-\frac{1-\alpha}{\epsilon}+1-\alpha} n_{1 i}^{-\frac{\alpha}{\epsilon}+\alpha}\left(w_{1 i}-x_{i}\right)^{\beta\left(\alpha-\frac{\alpha}{\epsilon}\right)-1}-P n_{1 i}=0 .
\end{gathered}
$$

Using these equations, each element of the Hessian at the equilibrium value is as follows:

$$
\begin{gathered}
a_{11}=\left(-\frac{\alpha}{\epsilon}+\alpha-1\right) n_{1 i}^{-1} P w_{1 i}<0, \\
a_{12}=\left(1-\alpha-\frac{1-\alpha}{\epsilon}\right) n_{2 i}^{-2} P w_{1 i}>0, \\
a_{13}=\left(\alpha-\frac{\alpha}{\epsilon}-1\right) P<0, \\
a_{21}=\left(-\frac{\alpha}{\epsilon}+\alpha\right) n_{1 i}^{-1} P w_{2 i}>0, \\
a_{22}=\left(-\alpha-\frac{1-\alpha}{\epsilon}\right) n_{2 i}^{-2} P w_{2 i}<0, \\
a_{23}=\left(-\frac{\alpha}{\epsilon}+\alpha\right) \beta\left(w_{1 i}-x_{i}\right)^{-1} P w_{2 i}>0, \\
a_{31}=P \frac{-\epsilon(1-\alpha)-\alpha}{\epsilon}<0, \\
a_{32}=P \frac{(1-\alpha)(\epsilon-1)}{\epsilon} n_{i 2}^{-1} n_{1 i}>0, \\
a_{33}=P\left[\beta \frac{\alpha(\epsilon-1)}{\epsilon}-1\right]\left(w_{1 i}-x_{i}\right)^{-1} n_{1 i}<0 .
\end{gathered}
$$

Using the above equations, we can derive the following conditional expressions:

$$
\begin{gathered}
a_{11} a_{22}-a_{12} a_{21}=\frac{P^{2} n_{1 i}^{-1} n_{2 i}^{-1} w_{1 i} w_{2 i}}{\epsilon}>0 \\
a_{21} a_{32}-a_{22} a_{31}=-\frac{P^{2} n_{2 i}^{-1} w_{2 i}}{\epsilon}<0 \\
a_{11} a_{32}-a_{12} a_{31}=0 .
\end{gathered}
$$

Using Eqs. (39) and (45)-(48), we obtain the following conditional equation:

$$
\begin{gathered}
a_{11} a_{22} a_{33}+a_{12} a_{23} a_{31}+a_{21} a_{23} a_{31}+a_{21} a_{32} a_{13}-a_{13} a_{22} a_{31}-a_{11} a_{23} a_{32}-a_{12} a_{21} a_{33} \\
=a_{33}\left(a_{11} a_{22}-a_{12} a_{21}\right)+a_{13}\left(a_{21} a_{32}-a_{22} a_{31}\right)+a_{23}\left(a_{11} a_{32}-a_{12} a_{31}\right)
\end{gathered}
$$




$$
=\frac{P^{3} n_{2 i}^{-1} w_{2 i}}{\epsilon} \times \frac{\beta-1}{\beta}<0 .
$$

Therefore, from Eqs. (37), (46), and (49), the Hessian of the equilibrium value is negative and definite and satisfies the second-order condition.

\section{Appendix 2}

From Eq. (22), we obtain the following equation:

$$
\frac{\partial u}{\partial l_{2}}=\beta c^{\beta-1}\left(w_{2}-w_{u}\right)\left(\bar{l}-l_{1}-l_{2}\right)^{1-\beta}-c^{\beta}(1-\beta)\left(\bar{l}-l_{1}-l_{2}\right)^{1-\beta}=0 .
$$

By transforming Eq. (50), we obtain the following equation:

$$
l_{2}=\beta\left(\bar{l}-l_{1}\right)-(1-\beta) \frac{w_{1} l_{1}+w_{u}\left(l-l_{1}\right)}{w_{2}-w_{u}} .
$$

Substituting Eq. (51) into $\bar{l}-l_{1}-l_{2}$, we obtain the following equation:

$$
\bar{l}-l_{1}-l_{2}=(1-\beta) \frac{w_{2} \bar{l}+\left(w_{1}-w_{2}\right) l_{1}}{w_{2}-w_{u}} .
$$

Finally, substituting Eqs. (51) and (52) into Eq. (21) gives Eq. (23).

\section{Appendix 3}

Using Eqs. (1) and (15), the total production, $Y=m y$, can be expressed as follows:

$$
\mathrm{Y}=\mathrm{A} \theta^{\alpha}\left(\frac{w_{1}}{w_{2}} \frac{1-\alpha}{\alpha}\right)^{1-\alpha} N_{1}
$$

Then, by substituting Eqs. (17), (19), and (53) into Eq. (18), we obtain the following equation:

$$
w_{2}=A^{\frac{1}{1-\alpha}} \beta^{\frac{\alpha \beta}{1-\alpha}} W_{1}^{\frac{\alpha(\beta-1)}{1-\alpha}} \alpha^{\frac{\alpha}{1-\alpha}}(1-\alpha)\left(1-\frac{1}{\epsilon}\right)^{\frac{1}{1-\alpha}} .
$$

Substituting Eq. (54) into Eq. (53) gives Eq. (28).

\section{Appendix 4}

Substituting Eqs. (28) and (54) into Eq. (29), we get the following formula:

$$
N_{1}=a\left[\beta w_{1} N_{1}+A^{\frac{1}{1-\alpha}} \beta^{\frac{\alpha \beta}{1-\alpha}+1} w_{1}^{\frac{\alpha(\beta-1)}{1-\alpha}} \alpha^{\frac{\alpha}{1-\alpha}}(1-\alpha)\left(1-\frac{1}{\epsilon}\right)^{\frac{1}{1-\alpha}}\left(L-N_{1}\right)+\gamma+\delta \frac{w_{1} N_{1}}{\epsilon-1}-\frac{w_{1} \epsilon}{\alpha(\epsilon-1)} N_{1}\right]
$$

Then, by substituting Eqs. (14), (15), and (54) into Eq. (30), we obtain the following equation:

$$
w_{1}=b\left\{\frac{1}{\alpha} w_{1} N_{1}+\left[L-N_{1}-w_{1}^{\frac{1-\alpha \beta}{1-\alpha}} A^{\frac{1}{\alpha-1}} \beta^{\frac{\alpha \beta}{\alpha-1}} \alpha^{\frac{1}{\alpha-1}}\left(1-\frac{1}{\epsilon}\right)^{\frac{1}{\alpha-1}} N_{1}\right] w_{u}-(1-\beta) w_{1} L\right\} .
$$

From Eqs. (55) and (56), the elements of the Hessian in the vicinity of the equilibrium value are as follows: 


$$
\begin{gathered}
b_{11}=a\left[\frac{w_{1}(\delta-\epsilon)}{\alpha(\epsilon-1)}+\beta\left(w_{1}-w_{2}\right)\right], \\
b_{12}=a\left[\beta \frac{N_{1}\left(w_{1}-w_{2}\right)+w_{2} L}{w_{1}}+\frac{(\delta-\epsilon) N_{1}}{\alpha(\epsilon-1)}\right], \\
b_{21}=b\left[\frac{w_{1}}{\alpha}+\frac{w_{1}(1-\alpha)+w_{2} \alpha}{w_{2} \alpha} w_{u}\right], \\
b_{22}=b\left[\frac{N_{1}}{\alpha}+\frac{N_{1} w_{u}(1-\alpha \beta)}{w_{2}}-(1-\beta) L\right] .
\end{gathered}
$$

Let $b_{11}<0, b_{22}<0$, and $|\operatorname{det}|=b_{11} b_{22}-b_{12} b_{21}>0$, and let this dynamic system be stable. Note that $b_{11}<0$ is said to be a Keynesian stability condition, which must be $\delta<\epsilon$ in order for it to hold.

From Eqs. (55)-(60), we obtain the following equations:

$$
\begin{aligned}
& \frac{d N_{1}}{d w_{u}}=-\frac{\left(L-N_{1}-N_{2}\right) b_{12}}{\mid \text { det } \mid}, \\
& \frac{d w_{1}}{d w_{u}}=-\frac{\left(L-N_{1}-N_{2}\right) b_{11}}{|\operatorname{det}|}>0 .
\end{aligned}
$$

From Eq. (54), $\frac{d w_{2}}{d w_{u}}<0$ holds, so that $\frac{d\left(\frac{w_{1}}{w_{2}}\right)}{d w_{u}}>0$. Therefore, from Eq. (54), $\frac{d\left(\frac{N_{1}}{N_{2}}\right)}{d w_{u}}<0$. Additionally, because the sign of $\frac{d N_{1}}{d w_{u}}$ is not fixed, the sign of $\frac{d N_{2}}{d w_{u}}$ is also not fixed.

\section{Appendix 5}

Considering Eq. (34), Eq. (55) can be rewritten as follows:

$$
\begin{gathered}
N_{1}=a\left\{\beta w_{1} N_{1}+A^{\frac{1}{1-\alpha}} \beta^{\frac{\alpha \beta}{1-\alpha}+1} w_{1}^{\frac{\alpha(\beta-1)}{1-\alpha}} \alpha^{\frac{\alpha}{1-\alpha}}(1-\alpha)\left(1-\frac{1}{\epsilon}\right)^{\frac{1}{1-\alpha}}\left(L-N_{1}\right)+\gamma+\delta\left[\frac{w_{1} N_{1}}{\epsilon-1}-(L-\right.\right. \\
\left.\left.\left.N_{1}-\frac{w_{1}}{w_{2}} \times \frac{1-\alpha}{\alpha} N_{1}\right) w_{u}\right]-\frac{w_{1} \epsilon}{\alpha(\epsilon-1)} N_{1}\right\} .
\end{gathered}
$$

Therefore, the following elements of the Hessian's system differ from previous systems.

$$
\begin{gathered}
b_{11}^{\prime}=a\left[\frac{w_{1}(\delta-\epsilon)}{\alpha(\epsilon-1)}+\beta\left(w_{1}-w_{2}\right)+\delta w_{u}\left(1+\frac{w_{1}}{w_{2}} \times \frac{1-\alpha}{\alpha}\right)\right], \\
b_{12}^{\prime}=\mathrm{a}\left[\beta N_{1}+w_{2} \beta\left(\mathrm{L}-N_{1}\right) \frac{\alpha(\beta-1)}{1-\alpha} w_{1}^{-1}+\frac{\delta-\epsilon}{(\epsilon-1) \alpha} N_{1}+\frac{1-\alpha}{\alpha} w_{u} N_{1} \frac{\partial\left(\frac{w_{1}}{w_{2}}\right)}{\partial w_{1}}\right] .
\end{gathered}
$$

Again, supposing that the stability conditions of $b_{11}^{\prime}<0, b_{22}^{\prime}<0,|\operatorname{det}|^{\prime}=b_{11}^{\prime} b_{22}-b_{12}^{\prime} b_{21}>$ 0 hold.

From Eqs. (55) and (63), we obtain the following equation:

$$
\begin{aligned}
\frac{d N_{1}}{d w_{u}} & =\frac{\left(L-N_{1}-N_{2}\right)\left(\delta b_{22}+b_{12}^{\prime}\right)}{|d e t|^{\prime}}, \\
\frac{d w_{1}}{d w_{u}} & =\frac{\left(L-N_{1}-N_{2}\right)\left(-b_{11}^{\prime}-\delta b_{21}\right)}{|\operatorname{det}|^{\prime}} .
\end{aligned}
$$




\section{REFERENCES}

Adachi, H. (2000) "The Determination of Prices, Wages and Employment under Imperfect Competition: Micro Foundations of Macroeconomics," The Annuals of Economic Studies, 46, 1-29. (in Japanese) http://www.lib.kobe-u.ac.jp/repository/00399353.pdf

Bowles, S. (2012) "Feasible Egalitarianism in a Competitive World," in The New Economics of Inequality and Redistribution. Cambridge: Cambridge University Press. 73-100. https:// ebooksumo.com/search/the-new-economics-of-inequality-and-redistribution/

Bowles, S. and Boyer, R. (1992) "A Wage-led Employment Regime: Income Distribution, Labor Discipline and Aggregate Demand in Welfare Capitalism," in S. Marglin and J. Schor (eds.) The Golden Age of Capitalism: Re-interpreting the Post-war Experience. Oxford: Clarendon. 187-217.

Nakatani, T. (2013) "Minimum Wages and Employment - in the Light of Dual Labor Market," Journal of the University of Marketing and Distribution Sciences. Distribution sciences \& business administration, 21(2), 91-105. (in Japanese) https://ryuka.repo.nii.ac.jp/?action=pages_ view_main\&active_action=repository_view_main_item_detaileitem_id=83\&item_ no=1\&page_id=13\&block_id=35

Onaran, O”. (2019) “Debate: Equality-led Development,” Development and Change, 50(2), 445-457. https://doi.org/10.1111/dech.12488

Radukic, S., Mastilo, Z., Kostic, Z. \& Vladusic, Lj. (2019) "Measuring of The Goods and Labor Markets Efficiency: Comparative Study of Western Balkan Countries," Montenegrin Journal of Economics, 15(2), 95-109. DOI: 10.14254/1800-5845/2019.15-2.8

Saint-Paul, G. (1997) Dual Labor Markets: A Macroeconomic Perspective. Cambridge: MIT Press Books. https://mitpress.mit.edu/books/dual-labor-markets

Sonoda, R. and Sasaki, H. (2019) "Differences in wage-determination systems between regular and non-regular employment in a Kaleckian model," Review of Keynesian Economics, 7(3), 341360. https://doi.org/10.4337/roke.2019.03.05

Skott, P. (2017) “Weaknesses of wage-led growth," Review of Keynesian Economics, 5(3), 336-359. https://doi.org/10.4337/roke.2017.03.03 